\title{
Poor Rhythm Outcome of Catheter Ablation for Early-Onset Atrial Fibrillation in Women
}

\author{
- Mechanistic Insight -
}

\author{
Hee Tae Yu, MD, PhD; Pil-Sung Yang, MD; Tae-Hoon Kim, MD; \\ Jae-Sun Uhm, MD, PhD; Jong-Youn Kim, MD, PhD; Boyoung Joung, MD, PhD; \\ Moon-Hyoung Lee, MD, PhD; Hui-Nam Pak, MD, PhD
}

\begin{abstract}
Background: Catheter ablation is a good treatment option for atrial fibrillation (AF) in young symptomatic patients. However, there is little information on the efficacy of catheter ablation of early-onset AF between sexes.

Methods and Results: This study included 1,060 patients under the age 60 years old (837 men, $49.8 \pm 7.7$ years old, $70.8 \%$ paroxysmal AF) who underwent catheter ablation for AF. Sex differences in clinical presentation and ablation outcomes were compared with and without propensity score-matching. During $24.5 \pm 18.9$ months of follow-up, women showed significantly higher clinical recurrence of $A F$ than men (log-rank, $P=0.002$ ). Female sex was independently associated with post-ablation clinical recurrence of $A F$ (adjusted hazard ratio $(H R) 2.58$ [1.06-6.30], $P=0.037)$. Women had a higher proportion of left ventricular diastolic dysfunction ( $E / E m, P<0.001)$, higher prevalence of heart failure $(P=0.017)$, greater left atrial $(L A)$ volume index $(P=0.001)$, lower $L A$ endocardial voltage $(P<0.001)$, and higher parasympathetic nervous activity (root-mean square of differences, $P<0.001$; high-frequency $(H F)$, $P=0.010)$ than men. After a second ablation procedure $(n=111)$, women still showed a higher clinical recurrence rate than men (log-rank, $\mathrm{P}=0.003$ ) during $22.9 \pm 15.0$ months of follow-up.
\end{abstract}

Conclusions: Among patients with early-onset AF who underwent catheter ablation, women showed poorer clinical outcomes than men after de novo and second procedures. Left ventricular dysfunction, LA remodeling, and autonomic nervous function may be potential mechanisms underlying sex differences in catheter ablation outcomes of early-onset AF.

Key Words: Atrial fibrillation; Catheter ablation; Recurrence; Sex differences

A trial fibrillation (AF) is known to have several different effects in men and women. The incidence or prevalence of AF has been reported to be lower in women than in men over all age groups. ${ }^{1}$ A number of studies have supported that female sex is an independent risk factor for AF-related stroke and thromboembolism. ${ }^{2,3}$ For this reason, female sex is taken into account in current clinical risk scoring systems, such as the $\mathrm{CHA}_{2} \mathrm{DS}_{2}-\mathrm{VASc}$ (congestive heart failure, hypertension, age $\geq 75$ years, diabetes mellitus, stroke, vascular disease, age 65-74 years, sex category) score. ${ }^{4}$ Treatment trends also differ, as women are less likely to undergo rhythm-control treatment than men; among individuals undergoing rhythm-control treatment, women are less likely to undergo pulmonary vein (PV) isolation (PVI). ${ }^{5}$ In addition, several previous studies reported higher $\mathrm{AF}$ recurrence rates after radiofrequency catheter ablation (RFCA) among women; however, those women tended to have a higher mean age, a higher preva-

\begin{abstract}
Editorial p 2244
lence of non-paroxysmal AF, and a longer history of $\mathrm{AF}$ before being considered for RFCA, which may have resulted in advanced electrical and structural remodeling of the left atrium (LA) in women. ${ }^{6}$

AF is a disease that occurs mainly in the elderly. A cutoff age of 60 years has been included in the diagnosis of lone AF or early-onset AF in several landmark epidemiological studies; for example, the Framingham Heart Study ${ }^{7}$ and the Mayo Clinic Study. ${ }^{8}$ Because AF was identified as a heritable disease, genetic traits may affect early-onset AF differently than AF in elderly patients. ${ }^{9}$ Currently, there are no clear data on the efficacy of RFCA between sexes among relatively younger patients with early-onset AF ( $<60$ years of age). The aim of the current study was to investigate the effect of sex on the outcome of AF catheter
\end{abstract}

Received December 10, 2017; revised manuscript received April 9, 2018; accepted April 25, 2018; released online June 8, 2018 Time for primary review: 15 days

Yonsei University Health System, Seoul, Republic of Korea

Mailing address: Hui-Nam Pak, MD, PhD, FHRS, Yonsei University Health System, 50-1 Yonsei-ro, Seodaemun-gu, Seoul 03722, Republic of Korea. E-mail: hnpak@yuhs.ac

ISSN-1346-9843 All rights are reserved to the Japanese Circulation Society. For permissions, please e-mail: cj@j-circ.or.jp 
A

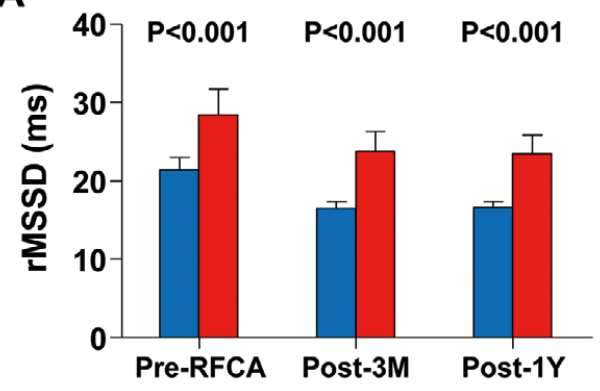

C

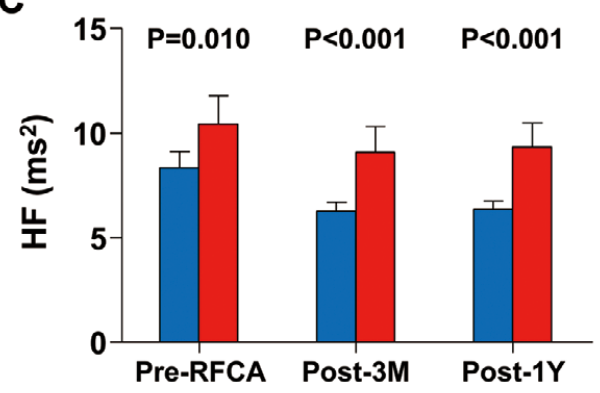

B

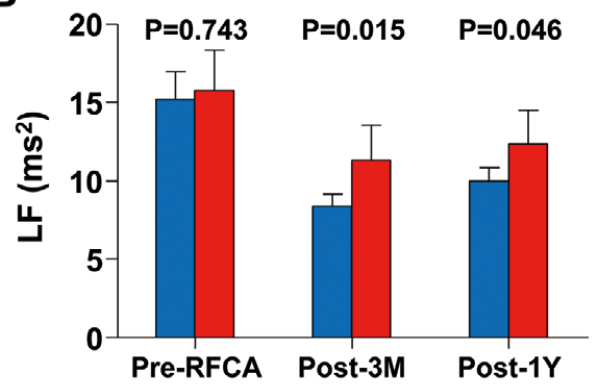

D

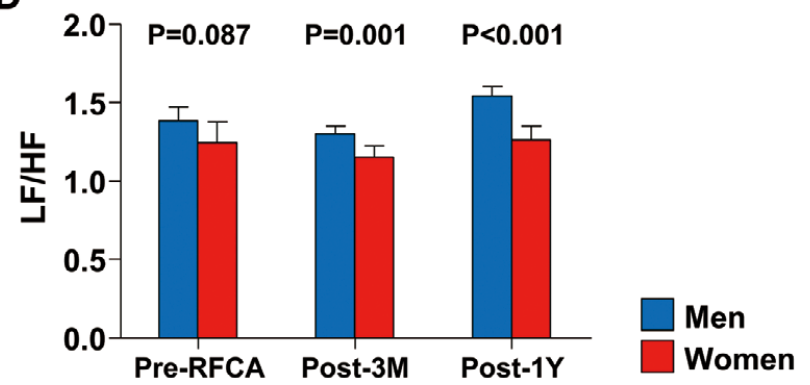

Figure 1. (A-D) Comparison of heart rate variability parameters between sexes. 1Y, 1 year; 3M, 3-month; HF, high-frequency components; LF, low-frequency components; RFCA, radiofrequency catheter ablation; rMSSD, root-mean square of differences.

ablation, especially in patients with AF under the age 60 years old.

\section{Methods}

\section{Study Population}

The study protocol adhered to the Declaration of Helsinki and was approved by the Institutional Review Board of the Yonsei University Health System. All patients provided written informed consent for inclusion in the Yonsei AF Ablation Cohort Database (registered at clinicaltrials. gov as NCT02138695). From March 2009 to April 2016, 1,989 patients who underwent RFCA for AF were enrolled in the cohort, of which 1,060 patients under the age of 60 years old were analyzed (837 males, $50 \pm 8$ years old, $71 \%$ paroxysmal AF). Exclusion criteria were as follows: (1) valvular AF, (2) structural heart disease other than left ventricular (LV) hypertrophy, (3) LA diameter $\geq 60 \mathrm{~mm}$, and (4) history of AF ablation or cardiac surgery. All antiarrhythmic drugs (AADs) were discontinued for a minimum of 5 half-lives before the procedure. Anticoagulation therapy was maintained before catheter ablation. Both transthoracic and transesophageal echocardiography (TEE) were performed before RFCA to determine whether patients had combined structural heart disease or LA thrombus. The anatomy of the LA and the PVs of all patients was imaged with 3D spiral computer tomography (CT) scans (64 Channel, Light Speed Volume CT, Philips, Brilliance 63, Amsterdam, The Netherlands).

\section{Electroanatomic Mapping}

Intracardiac electrograms were recorded using the Prucka CardioLab ${ }^{\mathrm{TM}}$ electrophysiology system (General Electric
Medical Systems, Inc., Milwaukee, WI, USA), and RFCA was performed in all patients using 3D electroanatomic mapping (NavX, St. Jude Medical, Inc., Minnetonka, MN, USA) merged with 3D spiral CT. Double trans-septal punctures were made, and multiview pulmonary venograms were obtained. Systemic anticoagulation was performed with intravenous heparin to maintain an activated clotting time of 350-400s during the procedure. For electroanatomic mapping, the 3D geometry of both the LA and the PVs was generated using the NavX system and then merged with 3D spiral CT images. LA electrogram voltage maps were generated during high right atrial pacing at $500 \mathrm{~ms}$ to prevent rate-dependent activation changes, after maintaining sinus rhythm by circumferential PVI (CPVI) with or without cardioversion. If frequently recurring AF persisted after 3attempts at cardioversion, no further efforts were made to generate a LA voltage map. We obtained the peak-to-peak amplitude of contact bipolar electrograms from 350 to 500 points on the LA endocardium, and the mean LA electrogram voltage was calculated.

\section{Echocardiographic Evaluation}

All patients underwent transthoracic echocardiography (Sonos 5500, Philips Medical Systems, Andover, MA, USA; Vivid 7, GE Vingmed Ultrasound, Horten, Norway) prior to RFCA. TEE was performed to exclude any intracardiac thrombi. The emptying velocity of the LA appendage was measured in all patients.

\section{Pericardial Fat Volume Measurement}

The pericardial fat volume was measured as described in our previous study. ${ }^{10}$ Briefly, CT scanning was performed within the week before RFCA (64 Channel, Light Speed 


\begin{tabular}{|c|c|c|c|c|c|c|c|}
\hline & \multicolumn{4}{|c|}{ Overall study population } & \multicolumn{3}{|c|}{ Propensity score-matched population } \\
\hline & $\begin{array}{c}\text { Total } \\
(n=1,060)\end{array}$ & $\begin{array}{c}\text { Men } \\
(n=837)\end{array}$ & $\begin{array}{l}\text { Women } \\
(n=223)\end{array}$ & $P$ value & $\begin{array}{c}\text { Men } \\
(n=573)\end{array}$ & $\begin{array}{l}\text { Women } \\
(n=215)\end{array}$ & $P$ value \\
\hline Age, years & $49.8 \pm 7.7$ & $49.5 \pm 7.4$ & $50.8 \pm 8.6$ & $0.025^{*}$ & $50.1 \pm 7.2$ & $50.8 \pm 8.4$ & 0.242 \\
\hline Paroxysmal AF, n (\%) & $751(70.8)$ & $599(71.6)$ & $152(68.2)$ & 0.320 & $408(71.2)$ & 149 (69.3) & 0.601 \\
\hline AF duration, months & $82.1 \pm 212.7$ & $85.4 \pm 222.5$ & $68.6 \pm 167.6$ & 0.549 & $82.3 \pm 212.9$ & $70.3 \pm 172.0$ & 0.675 \\
\hline $\mathrm{BSA}, \mathrm{m}^{2}$ & $1.85 \pm 0.19$ & $1.91 \pm 0.16$ & $1.64 \pm 0.14$ & $<0.001^{*}$ & $1.91 \pm 0.15$ & $1.64 \pm 0.14$ & $<0.001^{*}$ \\
\hline $\mathrm{BMI}, \mathrm{kg} / \mathrm{m}^{2}$ & $25.1 \pm 3.3$ & $25.5 \pm 3.1$ & $23.8 \pm 3.4$ & $<0.001^{*}$ & $25.3 \pm 2.9$ & $23.8 \pm 3.4$ & $<0.001^{*}$ \\
\hline \multicolumn{8}{|l|}{ Comorbidities } \\
\hline Heart failure, n (\%) & $87(8.2)$ & $60(7.2)$ & $27(12.1)$ & $0.017^{\star}$ & $44(7.7)$ & $20(9.3)$ & 0.457 \\
\hline Hypertension, n (\%) & 359 (33.9) & $301(36.0)$ & $58(26.0)$ & $0.005^{\star}$ & $169(29.5)$ & $56(26.0)$ & 0.340 \\
\hline Diabetes mellitus, $\mathrm{n}(\%)$ & $95(9.0)$ & $84(10.0)$ & $11(4.9)$ & $0.018^{*}$ & $37(6.5)$ & $11(5.1)$ & 0.480 \\
\hline Stroke or TIA, n (\%) & $87(8.2)$ & $68(8.1)$ & $19(8.5)$ & 0.848 & $48(8.4)$ & $17(7.9)$ & 0.831 \\
\hline Vascular disease, n (\%) & 77 (7.3) & $71(8.5)$ & $6(2.7)$ & $0.003^{*}$ & $17(3.0)$ & $5(2.3)$ & 0.626 \\
\hline $\mathrm{CHA}_{2} \mathrm{DS}_{2}$-VASc score & $1.0 \pm 1.1$ & $0.8 \pm 1.0$ & $1.6 \pm 0.8$ & $<0.001^{*}$ & $0.6 \pm 0.9$ & $1.6 \pm 0.8$ & $<0.001^{*}$ \\
\hline \multicolumn{8}{|l|}{ Echocardiography } \\
\hline LA diameter, mm & $40.7 \pm 6.5$ & $41.0 \pm 6.2$ & $39.5 \pm 7.5$ & $0.007^{\star}$ & $40.8 \pm 6.3$ & $39.2 \pm 7.2$ & $0.002^{*}$ \\
\hline $\mathrm{LAVI}, \mathrm{mL} / \mathrm{m}^{2}$ & $33.8 \pm 12.9$ & $33.0 \pm 12.0$ & $36.8 \pm 15.7$ & $0.001^{*}$ & $33.4 \pm 12.1$ & $35.6 \pm 14.0$ & $0.034^{*}$ \\
\hline LVEF, \% & $62.5 \pm 8.3$ & $62.1 \pm 8.5$ & $63.8 \pm 7.3$ & $0.008^{*}$ & $62.0 \pm 8.4$ & $63.8 \pm 6.9$ & $0.006^{*}$ \\
\hline $\mathrm{E} / \mathrm{Em}$ & $9.2 \pm 4.5$ & $8.8 \pm 3.7$ & $11.1 \pm 6.4$ & $<0.001^{*}$ & $8.6 \pm 3.0$ & $11.3 \pm 6.3$ & $<0.001^{*}$ \\
\hline LVEDD, mm & $50.1 \pm 4.3$ & $50.7 \pm 4.1$ & $48.0 \pm 4.7$ & $<0.001^{*}$ & $50.7 \pm 4.0$ & $47.9 \pm 4.6$ & $<0.001^{*}$ \\
\hline LAA emptying velocity, $\mathrm{cm} / \mathrm{s}$ & $53.7 \pm 23.4$ & $54.9 \pm 22.7$ & $49.3 \pm 25.1$ & $0.016^{*}$ & $53.2 \pm 22.7$ & $49.4 \pm 25.2$ & 0.125 \\
\hline \multicolumn{8}{|l|}{ CT/NavX $(n=870)$} \\
\hline $\mathrm{LA}$ volume/BSA, mL/m² & $75.8 \pm 25.0$ & $73.3 \pm 22.0$ & $85.6 \pm 32.5$ & $<0.001^{*}$ & $73.9 \pm 22.4$ & $83.2 \pm 30.0$ & $<0.001^{\star}$ \\
\hline Pericardial fat volume, $\mathrm{cm}^{3}$ & $105.2 \pm 47.1$ & $111.7 \pm 46.2$ & $78.5 \pm 41.4$ & $<0.001^{*}$ & $111.5 \pm 48.1$ & $79.1 \pm 41.6$ & $<0.001^{*}$ \\
\hline LA endocardial voltage, $\mathrm{mV}$ & $1.25 \pm 0.65$ & $1.32 \pm 0.66$ & $0.99 \pm 0.55$ & $<0.001^{*}$ & $1.32 \pm 0.66$ & $1.00 \pm 0.55$ & $<0.001^{*}$ \\
\hline LAA endocardial voltage, $\mathrm{mV}$ & $2.40 \pm 1.52$ & $2.57 \pm 1.55$ & $1.80 \pm 1.26$ & $<0.001^{*}$ & $2.55 \pm 1.56$ & $1.84 \pm 1.27$ & $<0.001^{*}$ \\
\hline LA peak pressure, $\mathrm{mmHg}$ & $21.4 \pm 9.3$ & $21.1 \pm 9.2$ & $22.4 \pm 9.4$ & 0.126 & $20.8 \pm 9.4$ & $22.2 \pm 8.8$ & 0.113 \\
\hline
\end{tabular}

${ }^{*} \mathrm{P}<0.05$. AF, atrial fibrillation; BMI, body mass index; BP, blood pressure; BSA, body surface area; CT, computed tomography; E/Em, early mitral inflow velocity over the early diastolic mitral annular velocity; LA, left atrium; LAA, LA appendage; LAVI, LA volume index; LV, left ventricle; LVEF, LV ejection fraction; LVEDD, LV end-diastolic dimension; TIA, transient ischemic attack.

Volume CT, Philips, Brilliance 63). Pericardial fat was defined as the adipose tissue within the pericardial sac, and the $\mathrm{CT}$ attenuation threshold for fat detection was between -190 and -30 Hounsfield units as used in a previous study. ${ }^{11}$ Two independent investigators who were blinded to the patients' clinical information quantified the pericardial fat using computer software (ITK-SNAP, Penn Image Computing and Science Laboratory, University of Pennsylvania, USA). ${ }^{\mathbf{2}}$ After semiautomatic segmentation, the pericardial fat volume was automatically interpolated.

\section{RFCA}

Details of the RFCA technique and strategy were described previously. ${ }^{13}$ Briefly, for CPVI ablation, continuous circumferential lesions were created at the level of the LA antrum encircling the right and left PVs (Figure 1A) guided by the NavX system using an open-irrigated, $3.5-\mathrm{mm}$ tip deflectable catheter at $30-35 \mathrm{~W}$ and $45^{\circ} \mathrm{C}$ (Thermocool, Johnson \& Johnson, Inc., Diamond Bar, CA, USA; Coolflex, St. Jude Medical). We performed CPVI and cavotricuspid isthmus ablation in all patients. The endpoints of both CPVI and cavotricuspid isthmus block were defined by bidirectional pacing. For patients with persistent $\mathrm{AF}$, we added a roof line, posterior-inferior line, and anterior line as a standard lesion set. At the operator's discretion, additional ablation of the superior vena cava (SVC), non-PV foci, or complex fractionated electrograms was conducted. The procedure ended when there was no immediate recurrence of AF within 10 min after cardioversion with an isoproterenol infusion $(5-10 \mu \mathrm{g} / \mathrm{min})$. Non-PV foci under isoproterenol infusion were also ablated.

We recommended a second ablation procedure to patients who had recurrent symptomatic, antiarrhythmic drug refractory AF/atrial tachycardia (AT) at 3 months after the de novo procedure. The ablation strategy for the second procedure was consistent with that of the first procedure, but increased attention was given to searching for and ablating non-PV foci in patients who did not show any reconnected PV potential (36.9\%).

\section{Holter Monitor Records and Heart Rate Variability (HRV) Analysis}

We used a GE Marquette MARS 8000 Holter analyzer (General Electric Medical System, Inc.) to analyze HRV by taking $24-\mathrm{h}$ Holter monitor recordings pre- and postablation at 3 and 12 months for each patient. After identifying each QRS complex, the numerical series of RR intervals was calculated. Only high-quality recordings were considered for analysis. All recordings were digitized and reviewed by an experienced operator. Premature ventricular beats, premature atrial beats, and electrical artifacts were excluded from analysis. HRV parameters were used as indicators of autonomic activity according to previously published guidelines. ${ }^{14}$ Mean HR and the follow- 


\begin{tabular}{|c|c|c|c|c|c|c|c|}
\hline & \multicolumn{4}{|c|}{ Overall study population } & \multicolumn{3}{|c|}{ Propensity score-matched population } \\
\hline & $\begin{array}{c}\text { Total } \\
(n=1,060)\end{array}$ & $\begin{array}{c}\text { Men } \\
(n=837)\end{array}$ & $\begin{array}{l}\text { Women } \\
(n=223)\end{array}$ & $P$ value & $\begin{array}{c}\text { Men } \\
(n=573)\end{array}$ & $\begin{array}{l}\text { Women } \\
(n=215)\end{array}$ & $P$ value \\
\hline Procedure time, $\min$ & $186.7 \pm 54.4$ & $186.9 \pm 55.2$ & $186.2 \pm 51.0$ & 0.881 & $184.2 \pm 53.3$ & $185.9 \pm 51.0$ & 0.679 \\
\hline Ablation time, $\mathrm{s}$ & $\begin{array}{c}4,668.0 \pm \\
1,759.2\end{array}$ & $\begin{array}{c}4,724.2 \pm \\
1,758.8\end{array}$ & $\begin{array}{c}4,459.6 \pm \\
1,749.0\end{array}$ & $0.046^{*}$ & $\begin{array}{c}4,696.1 \pm \\
1,757.0\end{array}$ & $\begin{array}{c}4,441.2 \pm \\
1,725.9\end{array}$ & 0.069 \\
\hline \multicolumn{8}{|l|}{ Additional ablation lesions } \\
\hline Roof line, $n(\%)$ & $458(43.5)$ & $354(42.6)$ & $104(46.8)$ & 0.257 & $242(42.5)$ & $98(45.8)$ & 0.412 \\
\hline Posterior-inferior line, n (\%) & $359(34.0)$ & $281(33.8)$ & $78(35.0)$ & 0.736 & $194(34.1)$ & $74(34.4)$ & 0.932 \\
\hline Anterior line, $n(\%)$ & 347 (32.9) & 269 (32.3) & $78(35.0)$ & 0.448 & $191(33.5)$ & $73(34.0)$ & 0.894 \\
\hline SVC-RA septal line, $n$ (\%) & $460(43.4)$ & $362(43.3)$ & $98(43.9)$ & 0.913 & $265(46.3)$ & $98(45.6)$ & 0.946 \\
\hline CFAE, n (\%) & $86(8.2)$ & $71(8.6)$ & $15(6.8)$ & 0.385 & $49(8.6)$ & $15(7.0)$ & 0.466 \\
\hline Major complications, n (\%) & $19(1.8)$ & $17(2.0)$ & $2(0.9)$ & 0.394 & $12(2.1)$ & $2(0.9)$ & 0.372 \\
\hline Hemopericardium, n (\%) & $12(1.1)$ & $11(1.3)$ & $1(0.4)$ & & $8(1.4)$ & $1(0.5)$ & \\
\hline Phrenic nerve palsy, n (\%) & $2(0.2)$ & $1(0.1)$ & $1(0.4)$ & & $1(0.2)$ & $1(0.5)$ & \\
\hline Minor stroke or TIA, n (\%) & $3(0.3)$ & $3(0.4)$ & 0 & & $2(0.3)$ & 0 & \\
\hline Femoral AV fistula, n (\%) & $2(0.2)$ & $2(0.2)$ & 0 & & $1(0.2)$ & 0 & \\
\hline \multicolumn{8}{|l|}{ Post-ablation medications } \\
\hline ACEI or ARB, n (\%) & $249(25.6)$ & $210(27.4)$ & $39(18.8)$ & $0.012^{*}$ & $127(24.1)$ & 39 (19.3) & 0.164 \\
\hline$\beta$-blockers, $n(\%)$ & $300(30.8)$ & $238(31.1)$ & $62(30.0)$ & 0.757 & $158(30.0)$ & $60(29.7)$ & 0.930 \\
\hline Statins, n (\%) & $180(18.5)$ & $135(17.6)$ & $45(21.7)$ & 0.176 & $78(14.8)$ & $44(21.8)$ & $0.025^{*}$ \\
\hline AAD at discharge, $n(\%)$ & $101(10.4)$ & $83(10.8)$ & $18(8.7)$ & 0.368 & $57(10.8)$ & $17(8.4)$ & 0.333 \\
\hline Follow-up duration, months & $24.5 \pm 18.9$ & $24.7 \pm 18.9$ & $23.9 \pm 18.7$ & 0.575 & $32.9 \pm 22.2$ & $35.4 \pm 22.5$ & 0.150 \\
\hline Early recurrence, n (\%) & $320(30.2)$ & $249(29.7)$ & $71(31.8)$ & 0.546 & $174(30.4)$ & $66(30.7)$ & 0.928 \\
\hline Clinical recurrence, n (\%) & $313(29.5)$ & $226(27.0)$ & $87(39.0)$ & $<0.001^{*}$ & $156(27.2)$ & $81(37.7)$ & $0.004^{*}$ \\
\hline $\mathrm{AF}$ at recurrence, $\mathrm{n}(\%)$ & $194(18.3)$ & $148(17.7)$ & $46(20.6)$ & $0039^{*}$ & $101(17.6)$ & $43(20.0)$ & م 081 \\
\hline AT at recurrence, $\mathrm{n}(\%)$ & $119(11.2)$ & $78(9.3)$ & $41(18.4)$ & $0.039^{n}$ & $55(9.6)$ & $38(17.7)$ & 0.081 \\
\hline
\end{tabular}

${ }^{*} \mathrm{P}<0.05$. AAD, antiarrhythmic drug; ACEI, angiotensin-converting-enzyme inhibitors; ARB, angiotensin II receptor blockers; AT, atrial tachycardia; $\mathrm{AV}$, arteriovenous; CFAE, complex fractionated atrial electrogram; RA, right atrium; SVC, superior vena cava. Other abbreviations as in Table 1.

ing time-domain HRV parameters were analyzed: the mean RR interval (mean NN interval), the standard deviation of $\mathrm{NN}$ intervals, the standard deviation of the 5-min means of NN intervals, and the root-mean square of differences between successive NN intervals (rMSSD). The following parameters were calculated: very-low-frequency components (VLF: $<0.04 \mathrm{~Hz}$ ), low-frequency components (LF: $0.04-0.15 \mathrm{~Hz}$ ), high-frequency components (HF: $0.15-0.40 \mathrm{~Hz}$ ), and the LF/HF ratio. HF and rMSSD are indicators of parasympathetic nervous activity, LF reflects sympathetic nervous activity, and the LF/HF ratio indicates the sympathovagal balance. ${ }^{14} \mathrm{We}$ excluded patients whose HRV was not analyzable because of sinus node dysfunction or a high number of $\mathrm{AF}$ episodes ( $>1$ time per hour or $>20$ times per day) or other arrhythmia episodes. Among a total of 1,060 patients, baseline HRV was not analyzed in 572 patients (men:women $=469: 103$ ), and there was no significant difference in the percentage of analyzable HRV data between men and women.

\section{Post-Ablation Follow-up}

We discharged patients without antiarrhythmic medication after the procedure $(82.2 \%)$, unless there was evidence of early recurrence of AF/AT or symptomatic frequent atrial premature beats. Patients visited the outpatient clinic regularly at $1,3,6$, and 12 months and then every 6 months thereafter, or whenever symptoms occurred after RFCA. All patients underwent electrocardiography (ECG) at each visit and 24-h Holter recording at 3 and 6 months and every 6 months thereafter. Holter monitoring or event monitor recordings were obtained when patients reported symptoms of palpitation suggestive of arrhythmia recurrence. AF recurrence was defined as any episode of AF or $\mathrm{AT} \geq 30 \mathrm{~s}$ in duration. Any ECG documentation of AF recurrence within a 3-month blanking period was diagnosed as an early recurrence, and AF recurrence more than 3 months after the procedure was diagnosed as a clinical recurrence.

\section{Statistical Analysis}

Continuous variables were summarized as the mean \pm SD and compared using Student's t-test and ANOVA. Categorical variables were summarized as a percentage of the group total and compared using the Chi-squared test or Fisher's exact test. Multivariate Cox regression analysis was used to identify predictors of clinical recurrence. Variables selected for multivariate analysis were those with P-value $<0.05$ in the univariate analysis (model 1 ) and clinical variables that showed significant sex differences in addition to those with P-value $<0.05$ in the univariate analysis (model 2 ). If there was significant correlation between selected variables $(R>0.5)$, only 1 variable was used to avoid multi-collinearity for multivariate regression analysis. Propensity scores were used to match men to women to reduce the potential confounding in this observational study. Propensity scores were estimated using a non-parsimonious multiple logistic regression model for men and women. The following variables were entered: age, type of $\mathrm{AF}$, and the comorbidities that make up the $\mathrm{CHA}_{2} \mathrm{DS}_{2}$-VASc score, which is also known as an impor- 
A. Total population

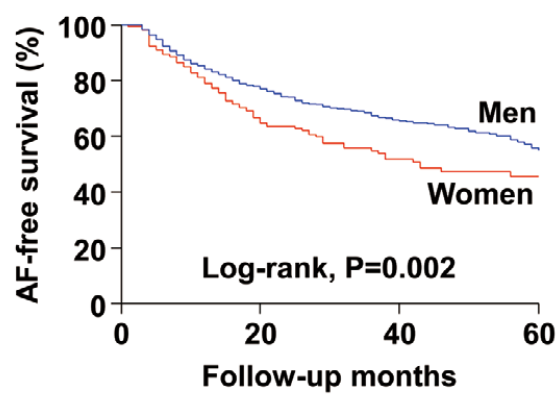

Number at risk

$$
\text { Men } 837
$$

Women 223

$$
\begin{aligned}
& 430 \\
& 106
\end{aligned}
$$

208

49

70
17

C. Propensity score-matched population

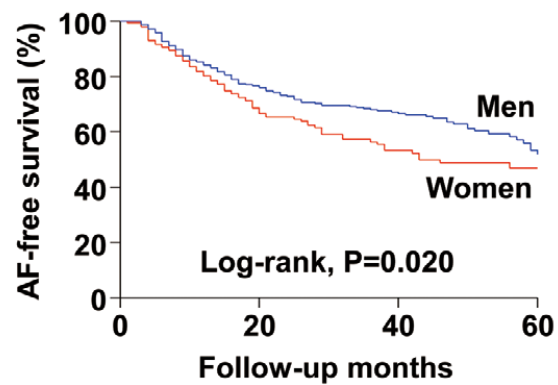

Number at risk

$\begin{array}{rcccc}\text { Men } & 573 & 288 & 139 & 39 \\ \text { Women } & 215 & 105 & 49 & 17\end{array}$

\section{B. Off-AAD in the total population}

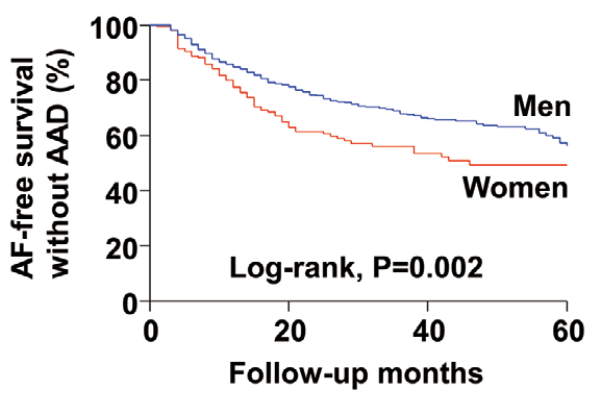

Number at risk

$\begin{array}{rcccc}\text { Men } & 730 & 369 & 173 & 61 \\ \text { Women } & 200 & 91 & 41 & 13\end{array}$

\section{Off-AAD in the propensity score-matched} population

\section{Number at risk}

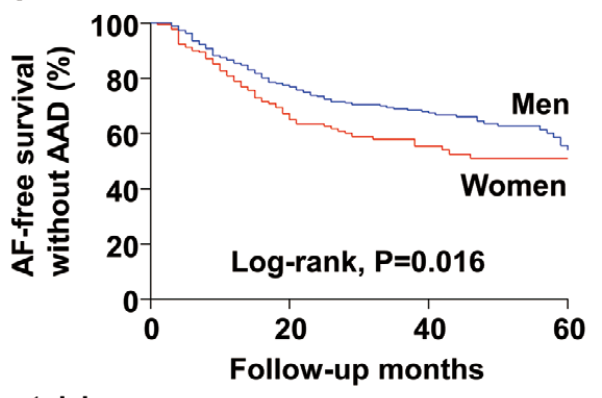

$\begin{array}{rcccc}\text { Men } & 507 & 255 & 117 & 34 \\ \text { Women } & 193 & 90 & 41 & 13\end{array}$

Figure 2. Kaplan-Meier analysis of atrial fibrillation $(A F)$ recurrence-free survival $(\mathbf{A}, \mathbf{C})$ and $A F$ recurrence-free survival off- $A A D$ $(\mathbf{B}, \mathbf{D})$ after catheter ablation between sexes within the total $(\mathbf{A}, \mathbf{B})$ and the propensity score-matched populations $(\mathbf{C}, \mathbf{D})$. AAD, antiarrhythmic drug.

tant score associated with recurrence after AF ablation. ${ }^{15,16}$ Cases were then matched, without replacement, with controls based on the closest possible value of the propensity score (nearest neighbor matching). A matching caliper of 0.1 standard deviations of the logit of the estimated propensity score was enforced to ensure that matches of poor fit were excluded. The matching procedure was performed using $\mathrm{R}$ packages ( $\mathrm{R}$ Foundation for Statistical Computing, Vienna, Austria), including Matchit, RItools, and CEM. Kaplan-Meier analysis with a log-rank test was used to calculate AF recurrence-free survival over time and to compare recurrence rates across sexes. A P-value $<0.05$ was considered to be statistically significant. Statistical analysis was performed using SPSS (version 20.0, Statistical Package for Social Sciences, Chicago, IL, USA) software for Windows.

\section{Results}

Baseline Characteristics

Comparison of the baseline characteristics between men $(n=837)$ and women $(n=223)$ is shown in Table 1. In com- parison to men, women were older $(\mathrm{P}=0.025)$, had lower body surface area $(\mathrm{P}<0.001)$ and body mass index $(\mathrm{BMI}$ : $\mathrm{P}<0.001)$, and were more likely to have heart failure $(\mathrm{P}=0.017)$. Although women had a lower prevalence of hypertension $(\mathrm{P}=0.005)$, diabetes mellitus $(\mathrm{P}=0.018)$, and vascular disease $(\mathrm{P}=0.003)$ than men, the mean $\mathrm{CHA}_{2} \mathrm{DS}_{2}-$ VASc score was approximately 1 point higher for women $(\mathrm{P}<0.001)$ because the current risk scoring system includes sex.

\section{Sex Differences in Electrical and Structural Remodeling and HRV}

Sex differences in electrical and structural remodeling were analyzed using echocardiographic and intraprocedural LA voltage measurements. In the preprocedural echocardiograms, the LA diameter $(39.5 \pm 7.5 \mathrm{~mm}$ vs. $41.0 \pm 6.2 \mathrm{~mm}$, $\mathrm{P}=0.007)$ and the $\mathrm{LV}$ end-diastolic dimension $(48.0 \pm 4.7 \mathrm{~mm}$ vs. $50.7 \pm 4.1 \mathrm{~mm}, \mathrm{P}<0.001)$ were shorter in women than in men, but the LA volume index was significantly higher in women than in men $\left(36.8 \pm 15.7 \mathrm{~mL} / \mathrm{m}^{2}\right.$ vs. $33.0 \pm 12.0 \mathrm{~mL} / \mathrm{m}^{2}$, $\mathrm{P}=0.001$ ) because of the women's lower body surface area as compared with men. Women were more likely than 
Table 3. Predictors for Clinical Recurrence of AF After Catheter Ablation

\begin{tabular}{|c|c|c|c|c|c|c|}
\hline & \multicolumn{2}{|c|}{ Univariate analysis } & \multicolumn{2}{|c|}{ Multivariate analysis (Model 1$)^{\dagger}$} & \multicolumn{2}{|c|}{ Multivariate analysis (Model 2) $)^{\ddagger}$} \\
\hline & HR $(95 \% \mathrm{Cl})$ & $P$ value & HR $(95 \% \mathrm{Cl})$ & $P$ value & $\mathrm{HR}(95 \% \mathrm{Cl})$ & $P$ value \\
\hline Female sex & $1.474(1.151-1.887)$ & $0.002^{*}$ & $2.582(1.059-6.295)$ & $0.037^{*}$ & $3.024(1.054-8.682)$ & $0.040^{*}$ \\
\hline Age & $0.994(0.980-1.009)$ & 0.450 & & & $0.986(0.923-1.054)$ & 0.684 \\
\hline Paroxysmal AF & $0.690(0.548-0.868)$ & $0.002^{*}$ & $0.505(0.153-1.671)$ & 0.263 & $0.605(0.165-2.224)$ & 0.450 \\
\hline AF duration & $1.001(1.000-1.001)$ & $0.037^{\star}$ & $1.001(0.999-1.002)$ & 0.260 & $1.001(0.999-1.002)$ & 0.291 \\
\hline BSA & $0.600(0.328-1.098)$ & 0.098 & & & & \\
\hline BMI & $1.001(0.968-1.036)$ & 0.933 & & & $0.976(0.893-1.066)$ & 0.582 \\
\hline Heart failure & $1.269(0.866-1.860)$ & 0.222 & & & $1.171(0.310-4.421)$ & 0.816 \\
\hline Hypertension & $0.987(0.782-1.247)$ & 0.915 & & & $1.031(0.393-2.706)$ & 0.951 \\
\hline Diabetes mellitus & $0.827(0.536-1.276)$ & 0.391 & & & $1.151(0.218-6.076)$ & 0.869 \\
\hline Stroke or TIA & $1.168(0.806-1.692)$ & 0.412 & & & & \\
\hline Vascular disease & $0.759(0.477-1.208)$ & 0.245 & & & $0.892(0.197-4.046)$ & 0.882 \\
\hline LAVI & $1.017(1.009-1.025)$ & $<0.001^{\star}$ & $1.022(0.996-1.048)$ & 0.105 & $1.024(0.994-1.056)$ & 0.120 \\
\hline LVEF & $0.987(0.975-0.999)$ & $0.032^{*}$ & $0.989(0.946-1.033)$ & 0.615 & $0.997(0.943-1.054)$ & 0.908 \\
\hline $\mathrm{E} / \mathrm{Em}$ & $1.001(0.976-1.027)$ & 0.934 & & & $0.962(0.847-1.093)$ & 0.553 \\
\hline $\begin{array}{l}\text { LA endocardial } \\
\text { voltage }\end{array}$ & $0.596(0.468-0.758)$ & $<0.001^{*}$ & $0.695(0.270-1.789)$ & 0.108 & $0.729(0.241-2.201)$ & 0.575 \\
\hline rMSSD & $0.996(0.987-1.005)$ & 0.363 & & & $1.018(0.997-1.040)$ & 0.097 \\
\hline LF & $0.991(0.980-1.001)$ & 0.089 & & & & \\
\hline $\mathrm{HF}$ & $0.988(0.968-1.008)$ & 0.229 & & & & \\
\hline LF/HF ratio & $0.823(0.694-0.976)$ & $0.025^{*}$ & $1.273(0.948-1.710)$ & 0.108 & $0.868(0.527-1.430)$ & 0.579 \\
\hline
\end{tabular}

${ }^{*} \mathrm{P}<0.05$. ${ }^{\dagger}$ Model 1: variables with $\mathrm{P}<0.05$ in univariate analysis. $\neq$ Model 2: variables that showed sex differences in addition to those with $\mathrm{P}<0.05$ in univariate analysis. $\mathrm{Cl}$, confidence interval; HF, high-frequency components; HR, hazard ratio; LF, low-frequency components; rMSSD, root-mean square of differences between successive NN intervals. Other abbreviations as in Table 1.

men to have LV diastolic dysfunction (E/Em: $11.1 \pm 6.4$ vs. $8.8 \pm 3.7, \mathrm{P}<0.001)$ and a significantly lower LA appendage emptying velocity $(49.3 \pm 25.1 \mathrm{~cm} / \mathrm{s}$ vs. $54.9 \pm 22.7 \mathrm{~cm} / \mathrm{s}$, $\mathrm{P}=0.016)$ on TEE (Table 1). The endocardial voltage of the LA $(0.99 \pm 0.55 \mathrm{mV}$ vs. $1.32 \pm 0.66 \mathrm{mV}, \mathrm{P}<0.001)$ and the LA appendage $(1.80 \pm 1.26 \mathrm{mV}$ vs. $2.57 \pm 1.55 \mathrm{mV}, \mathrm{P}<0.001)$ were significantly lower in women than in men (Table 1). After propensity score-matching accounting for age, type of AF, and the comorbidities that make up the $\mathrm{CHA}_{2} \mathrm{DS}_{2}-\mathrm{VASc}$ score, the matched population showed results consistent with the overall population in terms of sex differences in structural remodeling. In the preprocedural HRV analysis (Figure 1), the parasympathetic nervous activity was more enhanced in women than in men (rMSSD: $28.5 \pm 19.3 \mathrm{~ms}$ vs. $21.4 \pm 16.6 \mathrm{~ms}, \mathrm{P}<0.001$; HF: $10.4 \pm 7.7 \mathrm{~ms}^{2}$ vs. $8.3 \pm 8.0 \mathrm{~ms}^{2}$, $\mathrm{P}=0.010)$. These differences were observed after the procedure at 3 and 12 months. There were no significant differences in sympathetic nervous activity (LF or LF/HF ratio) between sexes.

\section{Procedural Characteristics and Clinical Outcome After Catheter Ablation of AF}

The procedural results and clinical outcomes are summarized in Table 2. The total procedure time was not statistically different between sexes $(186.2 \pm 51.0 \mathrm{~min}$ vs. $186.9 \pm 55.2 \mathrm{~min}, \mathrm{P}=0.881$ ), but $\mathrm{RF}$ energy delivery time was shorter in women than in men $(4,459.6 \pm 1,749.0 \mathrm{~s}$ vs. $4,724.2 \pm 1,758.8 \mathrm{~s}, \mathrm{P}=0.046)$. There were no differences in the rate of additional ablation lesions beyond CPVI, such as the roof line, posterior-inferior line, anterior line, SVC to right atrial septal line and complex fractionated atrial electrogram ablation between sexes. The usage of AADs at discharge $(8.7 \%$ vs. $10.8 \%, \mathrm{P}=0.368)$ and other postprocedural medication use were comparable between men and women (Table 2).

During $24.5 \pm 18.9$ months of follow-up after AF ablation, women showed a significantly higher clinical recurrence of AF than was observed in men $(39.0 \%$ vs. $27.0 \%$, $\mathrm{P}<0.001)$. This finding was also confirmed in the propensity score-matched population (women vs. men: $37.7 \%$ vs. $27.2 \%, \mathrm{P}=0.004)$. The Kaplan-Meier analysis also showed a significantly higher clinical recurrence of $\mathrm{AF}$ in women than in men for the entire patient group (Figure 2A: log-rank, $\mathrm{P}=0.002$ ) and the patients off-AADs (Figure 2B: LOG-rank, $\mathrm{P}=0.002$ ). Among the propensity score-matched population, the difference between women and men for AF recurrence after catheter ablation remained significant for the entire patient group (Figure 2C: $\log$-rank, $\mathrm{P}=0.020$ ) and the patients off-AADs (Figure 2D: log-rank, $\mathrm{P}=0.016$ ). In addition, women were more likely to have an AT recurrence rather than an $\mathrm{AF}$ recurrence as compared with men $(18.4 \%$ vs. $9.3 \%, \mathrm{P}=0.039)$. In the multivariate Cox regression analysis (Table 3), the female sex was independently associated with a higher recurrence of $\mathrm{AF}$ after catheter ablation (Model 1: adjusted hazard ratio [HR] 2.58, 95\% confidence interval [CI] 1.06-6.30, P=0.037; Model 2: adjusted HR 3.02, 95\% CI 1.05-8.68, $\mathrm{P}=0.040$ ).

\section{Clinical Outcomes After the Second Ablation Procedure}

We also analyzed the characteristics and procedural outcomes of 111 patients who underwent a second ablation procedure after AF recurrence (Table 4). Among these patients, PVI was maintained and PV potential was not seen in $41(36.9 \%)$ individuals. There were no significant differences between the sexes in the repeat ablation rate among the patients with clinical recurrence (women vs. men: $29.9 \%$ vs. $37.6 \%, \mathrm{P}=0.201)$ in the time interval between the first and second procedures, in the PV recon- 


\begin{tabular}{|c|c|c|c|}
\hline & $\begin{array}{c}\text { Men } \\
(n=85)\end{array}$ & $\begin{array}{c}\text { Women } \\
(n=26)\end{array}$ & $P$ value \\
\hline Interval between procedures, months & $28.5 \pm 23.1$ & $27.5 \pm 18.8$ & 0.844 \\
\hline PV reconnection, $\mathrm{n}(\%)$ & $57(67.1)$ & $13(50.0)$ & 0.115 \\
\hline No. of reconnected PV, $\mathrm{n}(\%)$ & & & 0.064 \\
\hline PVP $1+$ & $8(9.4)$ & $6(23.1)$ & \\
\hline PVP 2+ & $22(25.9)$ & $3(11.5)$ & \\
\hline PVP 3+ & $14(16.5)$ & $1(3.8)$ & \\
\hline PVP 4+ & $13(15.3)$ & $3(11.5)$ & \\
\hline \multicolumn{4}{|l|}{ Additional ablation lesions, n (\%) } \\
\hline Roof line & $57(67.1)$ & $19(76.0)$ & 0.395 \\
\hline Posterior-inferior line & $45(54.2)$ & $13(50.0)$ & 0.845 \\
\hline Anterior line & $53(62.4)$ & $17(65.4)$ & 0.779 \\
\hline \multicolumn{4}{|l|}{ Bidirectional block, n (\%) } \\
\hline Roof line $(n=48 / 14)$ & $26(54.2)$ & $8(57.1)$ & 0.844 \\
\hline Posterior-inferior line $(n=41 / 13)$ & $12(29.3)$ & $7(53.8)$ & 0.106 \\
\hline Anterior line $(n=36 / 11)$ & $13(36.1)$ & $3(27.3)$ & 0.588 \\
\hline \multicolumn{4}{|l|}{ Mapping findings, $\mathrm{n}(\%)$} \\
\hline Unmappable & $26(30.6)$ & $8(30.8)$ & 0.986 \\
\hline Mappable & & & 0.393 \\
\hline Reentrant & $26(30.6)$ & $10(38.5)$ & \\
\hline Non-reentrant & $33(38.8)$ & $8(30.8)$ & \\
\hline LA endocardial voltage, $m V(n=87)$ & $1.15 \pm 0.66$ & $0.83 \pm 0.55$ & $0.042^{*}$ \\
\hline LAA endocardial voltage, $m V(n=86)$ & $2.35 \pm 1.40$ & $1.40 \pm 1.07$ & $0.005^{\star}$ \\
\hline LA peak pressure, $\mathrm{mmHg}$ & $24.9 \pm 12.7$ & $27.6 \pm 11.2$ & 0.337 \\
\hline Follow-up duration, months & $24.8 \pm 15.3$ & $16.6 \pm 12.4$ & $0.014^{\star}$ \\
\hline Early recurrence, $n(\%)$ & $28(32.9)$ & $6(23.1)$ & 0.340 \\
\hline Clinical recurrence, $n(\%)$ & $24(28.2)$ & $13(50.0)$ & $0.039^{*}$ \\
\hline
\end{tabular}

${ }^{*} \mathrm{P}<0.05$. PV, pulmonary vein; PVP, PV potential. Other abbreviations as in Table 1.

nection rate, in the generation of additional ablation lesions, or in the bidirectional block maintenance rates for the roof line, posterior-inferior line, and anterior line. AF or AT was induced in approximately $70 \%$ of the patients at the time of the second procedure, but there was no difference in the recurrence mechanism (reentrant or nonreentrant) between the sexes $(\mathrm{P}=0.393)$. Despite a shorter follow-up duration in women when compared with men (16.6 \pm 12.4 months vs. $24.8 \pm 15.3$ months, $\mathrm{P}=0.014$ ), the clinical recurrence rate after the second procedure was significantly higher in women than in men $(50.0 \%$ vs. $28.2 \%, \mathrm{P}=0.039$, Table 4). The Kaplan-Meier analysis showed a higher clinical recurrence of AF in women than in men (log-rank, $\mathrm{P}=0.003)$ during the $22.9 \pm 15.0$ months of follow-up (Figure 3).

\section{Discussion}

\section{Main Findings}

In the current study, we found that among early-onset AF patients women showed a significantly higher clinical recurrence of AF than observed in men. Female sex was independently associated with a higher recurrence of AF after catheter ablation among the total and propensity score-matched populations. Women were more likely than men to have LV diastolic dysfunction, a greater LA volume, a lower LA endocardial voltage, and a higher prevalence of heart failure. Parasympathetic nervous activity was more enhanced in women than in men according to

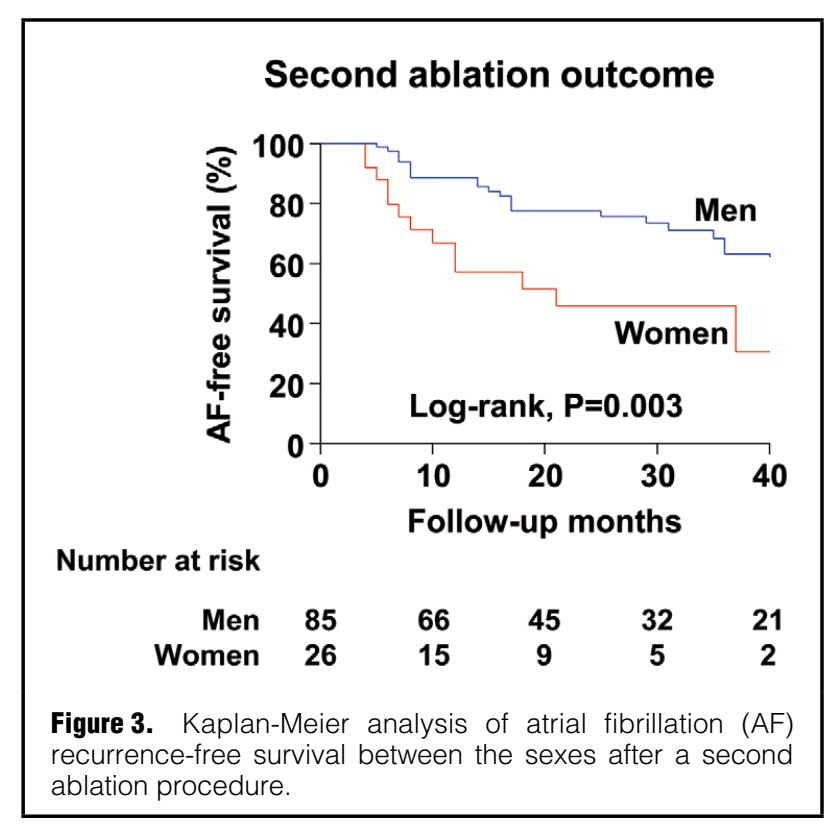

the HRV analysis. In addition, among patients who underwent a second ablation after AF recurrence, women also showed a higher clinical recurrence rate than men. 


\section{Sex Differences in AF}

Sex-specific differences in the epidemiology, pathophysiology, presentation, prognosis, and treatment of $\mathrm{AF}$ are becoming increasingly recognized. Women with AF generally experience worse symptoms and poorer quality of life. ${ }^{17}$ Female sex has been shown to be a risk factor for AF-related stroke or thromboembolism, myocardial infarction, and death. ${ }^{2}$ In addition, women are less likely to undergo electrical cardioversion and catheter ablation and, in some studies, less likely to receive anticoagulation despite their higher stroke risk. ${ }^{18}$ In previous unmatched retrospective studies, women were found to have a higher risk of AF recurrence after RFCA than men. ${ }^{19}$ The underlying mechanism of increased AF recurrence after RFCA in women has not been established. In those studies, women were older with a greater prevalence of non-paroxysmal AF and structural heart disease at the time of ablation. ${ }^{6}$ Moreover, women were referred later in the course of the disease and after treatment failure with more AADs. ${ }^{20}$ However, there was no significant sex difference in the clinical outcome of RFCA for AF when analyzed for overall age groups in our AF ablation cohort. Subgroup analysis of patients aged 60 years or older showed a tendency for higher recurrence in men, but the difference was reduced after 4 years of follow-up (Figure S1). One possible explanation is that the LA wall is probably thin in elderly women, so long-lasting CPVI seems to be easier to maintaining sinus rhythm after AF ablation. On the other hand, we observed a poorer outcome in women than in men under the age of 60 years old. Although there were no differences in the rate of additional extra-PV ablation between sexes (Table 2), the relative extent of ablation could be higher in women because of their smaller LA size. Yang et al reported that small LA size is significantly associated with recurrence as AT after AF ablation, irrespective of potential ablation gap in linear lesion. ${ }^{21}$ Currently, sex-specific clinical predictors of the maintenance of sinus rhythm, especially in patients with early-onset AF, have not been thoroughly investigated.

\section{Effects of Autonomic Nervous System in AF Ablation}

It is known that the autonomic nervous system plays an important role in the regulation of the cardiovascular system. ${ }^{22}$ With HRV analysis, the HF fluctuation of the RR interval mainly reflects vagal modulation and the inspiratory inhibition of vagal tone, whereas the LF components influence the baroreceptor-mediated regulation of blood pressure and reflect predominantly sympathetic activity. ${ }^{23}$ A number of studies have shown relationships between cardiac autonomic nerve function and AF in various animal models and in humans. ${ }^{24,25}$ The parasympathetic nerve fibers innervate the atria through an epicardial fat pad at the origin of the PV complex. ${ }^{26} \mathrm{~A}$ change in $\mathrm{HRV}$ after PV ablation has been demonstrated, and several investigators have also noted vagal reflexes during RF ablation of the PVs. ${ }^{27}$ In addition, we previously documented that ablation from the SVC to the right atrial septum after PVI also showed a vagal denervation effect and better clinical outcomes. ${ }^{28} \mathrm{We}$ also demonstrated that high sinus HR after AF ablation was associated with significant vagal modulation and a lower clinical recurrence of AF after RFCA. ${ }^{29}$

The sex-related differences in the autonomic nervous system have been studied previously. Umetani et al defined the effect of sex on HRV at different ages, ${ }^{30}$ and another study demonstrated that the sex-related difference in para- sympathetic regulation diminishes after the age of 50 years old and that women had a higher HF in the age strata of 40-49 years old. ${ }^{31}$ In the current study with AF patients under 60 years old, parasympathetic nervous activity was further enhanced in women than in men before and after RFCA. This finding may provide a partial explanation for the poor outcome observed in young women after AF ablation. Previously, a significant negative correlation was reported between HRV parameters such as rMSSD or HF, which reflects parasympathetic nervous activity and physical activity or the work stressor index..$^{32}$ The enhanced parasympathetic nervous activity in young women could be partly because of less activity by women than by men.

\section{Sex Difference in Atrial Remodeling}

AF is known to drive electrical and structural remodeling of atria, but the mechanism remains to be elucidated. Sustained atrial excitation results in various inflammatory responses such as oxidative stress, calcium overload, and myofibroblast activation. These inflammatory responses may lead to deformation of the extracellular matrix and of the electrophysiological properties of the atria, ${ }^{33}$ and may be more severe in women than in men. The Womens Health Study demonstrated that inflammatory markers such as high-sensitivity C-reactive protein, soluble intercellular adhesion molecule-1, and fibrinogen were associated with incident $\mathrm{AF}$ in women even after controlling for traditional risk factors. ${ }^{34}$ In addition, we have reported more advanced LA remodeling and LA appendage contractile dysfunction in women than in men among AF patients with a high calculated risk of stroke. ${ }^{35}$ In the current study, atrial remodeling was more pronounced even in young women when compared with men of the same age. Further research is needed to determine the contribution of these findings to the poor rhythm outcomes in women.

A previous study reported that pericardial fat volume measured by CT was associated with prevalent AF after adjustment for AF risk factors. ${ }^{11}$ Another study has suggested that LA epicardial adiposity is predictive of ablation outcomes, providing evidence of a particular role of pericardial fat, a unique fat deposit in close anatomic proximity to cardiac structures and autonomic fibers, in substrate remodeling of the atria after catheter ablation. ${ }^{36}$ In our study population, women who had a recurrence after RFCA had a significantly larger pericardial fat volume than women who did not have a recurrence. When the Kaplan-Meier curves were drawn with sex and the median value of the pericardial fat volume, AF recurrence after RFCA was significantly more frequent in women with large pericardial fat volume (Figure S2, log-rank, $\mathrm{P}=0.004$ ). Further investigations into the mechanisms linking pericardial fat to sex differences in AF ablation outcomes are warranted.

\section{Study Limitations}

We acknowledge that this was an observational study of a single-center prospective cohort that included a highly selected group of patients referred for AF catheter ablation. A validation study in a separate group will help to determine the sex differences in outcomes of AF ablation among early-onset AF patients. Although we performed propensity score-matching regarding age, type of $\mathrm{AF}$, and the comorbidities that make up the $\mathrm{CHA}_{2} \mathrm{DS}_{2}-\mathrm{VASc}$ score, there remained significant differences between sexes such as BMI, LA volume, LV ejection fraction, and $\mathrm{E} / \mathrm{Em}$, all 
of which can be associated with the clinical outcome after $\mathrm{AF}$ ablation. We performed a multivariate Cox regression analysis to offset this limitation, and the female sex was still independently associated with a higher recurrence of AF after catheter ablation after adjusting these confounders. Also, although we strictly followed the 2012 HRS/EHRA/ ECAS Expert Consensus Statement guidelines for rhythm monitoring after the procedure, some asymptomatic recurrences may not have been detected during the followup period.

\section{Conclusions}

In patients with early-onset $\mathrm{AF}$ who underwent catheter ablation, women showed poorer clinical outcomes after both the de novo and second procedures. LV dysfunction, LA remodeling, and autonomic nervous function may be considered when examining the in-depth mechanisms of the sex difference in early-onset AF.

\section{Sources of Funding}

This work was supported by a grant (A085136) from the Korea Health 21 R\&D Project, Ministry of Health and Welfare and a grant (NRF-2017R1A2B4003983, 2017R1C1B1008292) from the National Research Foundation of Korea funded by the Ministry of Education, Science and Technology.

\section{Disclosures}

None.

\section{References}

1. Ko D, Rahman F, Schnabel RB, Yin X, Benjamin EJ, Christophersen IE. Atrial fibrillation in women: Epidemiology, pathophysiology, presentation, and prognosis. Nat Rev Cardiol 2016; 13: $321-332$.

2. Bushnell C, McCullough LD, Awad IA, Chireau MV, Fedder WN, Furie KL, et al. Guidelines for the prevention of stroke in women: A statement for healthcare professionals from the American Heart Association/American Stroke Association. Stroke 2014; 45: 1545-1588.

3. Bekwelem W, Connolly SJ, Halperin JL, Adabag S, Duval S, Chrolavicius S, et al. Extracranial systemic embolic events in patients with nonvalvular atrial fibrillation: Incidence, risk factors, and outcomes. Circulation 2015; 132: 796-803.

4. Lip GY, Nieuwlaat R, Pisters R, Lane DA, Crijns HJ. Refining clinical risk stratification for predicting stroke and thromboembolism in atrial fibrillation using a novel risk factor-based approach: The Euro Heart Survey on Atrial Fibrillation. Chest 2010; 137: 263-272.

5. Avgil Tsadok M, Gagnon J, Joza J, Behlouli H, Verma A, Essebag V, et al. Temporal trends and sex differences in pulmonary vein isolation for patients with atrial fibrillation. Heart Rhythm 2015; 12: 1979-1986.

6. Vallakati A, Reddy M, Sharma A, Kanmanthareddy A, Sridhar A, Pillarisetti J, et al. Impact of gender on outcomes after atrial fibrillation ablation. Int J Cardiol 2015; 187: 12-16.

7. Brand FN, Abbott RD, Kannel WB, Wolf PA. Characteristics and prognosis of lone atrial fibrillation: 30 -year follow-up in the Framingham Study. JAMA 1985; 254: 3449-3453.

8. Jahangir A, Lee V, Friedman PA, Trusty JM, Hodge DO, Kopecky SL, et al. Long-term progression and outcomes with aging in patients with lone atrial fibrillation: A 30-year follow-up study. Circulation 2007; 115: 3050-3056.

9. Lee JY, Kim TH, Yang PS, Lim HE, Choi EK, Shim J, et al. Korean atrial fibrillation network genome-wide association study for early-onset atrial fibrillation identifies novel susceptibility loci. Eur Heart $J$ 2017; 38: 2586-2594.

10. Kim TH, Park J, Park JK, Uhm JS, Joung B, Lee MH, et al. Pericardial fat volume is associated with clinical recurrence after catheter ablation for persistent atrial fibrillation, but not paroxysmal atrial fibrillation: An analysis of over 600-patients. Int $J$ Cardiol 2014; 176: 841-846.

11. Thanassoulis G, Massaro JM, O’Donnell CJ, Hoffmann U, Levy
D, Ellinor PT, et al. Pericardial fat is associated with prevalent atrial fibrillation: The Framingham Heart Study. Circ Arrhythm Electrophysiol 2010; 3: 345-350.

12. Yushkevich PA, Piven J, Hazlett HC, Smith RG, Ho S, Gee JC, et al. User-guided 3D active contour segmentation of anatomical structures: Significantly improved efficiency and reliability. Neuroimage 2006; 31: 1116-1128.

13. Kim TH, Uhm JS, Kim JY, Joung B, Lee MH, Pak HN. Does additional electrogram-guided ablation after linear ablation reduce recurrence after catheter ablation for longstanding persistent atrial fibrillation?: A prospective randomized study. $\mathrm{J} \mathrm{Am}$ Heart Assoc 2017; 6: e004811.

14. Task Force of the European Society of Cardiology and the North American Society of Pacing and Electrophysiology. Heart rate variability: Standards of measurement, physiological interpretation and clinical use. Circulation 1996; 93: 1043-1065.

15. Chao TF, Tsao HM, Lin YJ, Tsai CF, Lin WS, Chang SL, et al. Clinical outcome of catheter ablation in patients with nonparoxysmal atrial fibrillation: Results of 3-year follow-up. Circ Arrhythm Electrophysiol 2012; 5: 514-520.

16. Jacobs V, May HT, Bair TL, Crandall BG, Cutler M, Day JD, et al. The impact of risk score (CHADS2 versus CHA2DS2-VASc) on long-term outcomes after atrial fibrillation ablation. Heart Rhythm 2015; 12: 681-686.

17. Dagres N, Nieuwlaat R, Vardas PE, Andresen D, Levy S, Cobbe $\mathrm{S}$, et al. Gender-related differences in presentation, treatment, and outcome of patients with atrial fibrillation in Europe: A report from the Euro Heart Survey on Atrial Fibrillation. $J$ Am Coll Cardiol 2007; 49: 572-577.

18. Hsu JC, Maddox TM, Kennedy KF, Katz DF, Marzec LN, Lubitz SA, et al. Oral anticoagulant therapy prescription in patients with atrial fibrillation across the spectrum of stroke risk: Insights from the NCDR PINNACLE registry. JAMA Cardiol 2016; 1: 55-62.

19. Patel D, Mohanty P, Di Biase L, Sanchez JE, Shaheen MH, Burkhardt JD, et al. Outcomes and complications of catheter ablation for atrial fibrillation in females. Heart Rhythm 2010; 7: $167-172$.

20. Forleo GB, Tondo C, De Luca L, Dello Russo A, Casella M, De Sanctis V, et al. Gender-related differences in catheter ablation of atrial fibrillation. Europace 2007; 9: 613-620.

21. Yang PS, Park YA, Kim TH, Uhm JS, Joung B, Lee MH, et al. Which patients recur as atrial tachycardia rather than atrial fibrillation after catheter ablation of atrial fibrillation? PLoS One 2017; 12: e0188326.

22. Levy MN. Autonomic interactions in cardiac control. Ann N Y Acad Sci 1990; 601: 209-221.

23. Pomeranz B, Macaulay RJ, Caudill MA, Kutz I, Adam D, Gordon D, et al. Assessment of autonomic function in humans by heart rate spectral analysis. Am J Physiol 1985; 248: H151H153.

24. Ng J, Villuendas R, Cokic I, Schliamser JE, Gordon D, Koduri $\mathrm{H}$, et al. Autonomic remodeling in the left atrium and pulmonary veins in heart failure: Creation of a dynamic substrate for atrial fibrillation. Circ Arrhythm Electrophysiol 2011; 4: 388-396.

25. Vaseghi M, Lux RL, Mahajan A, Shivkumar K. Sympathetic stimulation increases dispersion of repolarization in humans with myocardial infarction. Am J Physiol Heart Circ Physiol 2012; 302: $\mathrm{H} 1838-\mathrm{H} 1846$.

26. Chiou CW, Eble JN, Zipes DP. Efferent vagal innervation of the canine atria and sinus and atrioventricular nodes: The third fat pad. Circulation 1997; 95: 2573-2584.

27. Yamaguchi Y, Kumagai K, Nakashima H, Saku K. Long-term effects of box isolation on sympathovagal balance in atrial fibrillation. Circ J 2010; 74: 1096-1103.

28. Kang KW, Pak HN, Park J, Park JG, Uhm JS, Joung B, et al. Additional linear ablation from the superior vena cava to right atrial septum after pulmonary vein isolation improves the clinical outcome in patients with paroxysmal atrial fibrillation: Prospective randomized study. Europace 2014; 16: $1738-1745$.

29. Yu HT, Kim TH, Uhm JS, Kim JY, Joung B, Lee MH, et al. Prognosis of high sinus heart rate after catheter ablation for atrial fibrillation. Europace 2016; 19: 1132-1139.

30. Umetani K, Singer DH, McCraty R, Atkinson M. Twenty-four hour time domain heart rate variability and heart rate: Relations to age and gender over nine decades. J Am Coll Cardiol 1998; 31: 593-601.

31. Kuo TB, Lin T, Yang CC, Li CL, Chen CF, Chou P. Effect of aging on gender differences in neural control of heart rate. Am J Physiol 1999; 277: H2233-H2239. 
32. Tonello L, Rodrigues FB, Souza JW, Campbell CS, Leicht AS, Boullosa DA. The role of physical activity and heart rate variability for the control of work related stress. Front Physiol 2014; 5: 67.

33. Jalife J, Kaur K. Atrial remodeling, fibrosis, and atrial fibrillation. Trends Cardiovasc Med 2015; 25: 475-484.

34. Conen D, Ridker PM, Everett BM, Tedrow UB, Rose L, Cook $\mathrm{NR}$, et al. A multimarker approach to assess the influence of inflammation on the incidence of atrial fibrillation in women. Eur Heart J 2010; 31: 1730-1736.

35. Yu HT, Lee JS, Kim TH, Uhm JS, Joung B, Hong GR, et al. Advanced left atrial remodeling and appendage contractile dysfunction in women than in men among the patients with atrial fibrillation: Potential Mechanism for stroke. J Am Heart Assoc 2016; 5: e003361

36. Batal O, Schoenhagen P, Shao M, Ayyad AE, Van Wagoner
DR, Halliburton SS, et al. Left atrial epicardial adiposity and atrial fibrillation. Circ Arrhythm Electrophysiol 2010; 3: 230-236.

\section{Supplementary Files}

\section{Supplementary File 1}

Figure S1. Kaplan-Meier analysis of atrial fibrillation (AF) recurrence-free survival after catheter ablation between sexes in $(\mathbf{A})$ all age groups and (B) patients older than 60 years.

Figure S2. Kaplan-Meier analysis of atrial fibrillation (AF) recurrence-free survival after catheter ablation plotted by sex and pericardial fat volume (PFV).

Please find supplementary file(s);

http://dx.doi.org/10.1253/circj.CJ-17-1358 